\title{
KONSTRUKSI MAKNA HIJAB FASHION BAGI MOSLEM FASHION BLOGGER
}

\author{
Ade Nur Istiani \\ Jurusan Ilmu Komunikasi Fakultas Ilmu Sosial dan Ilmu Politik Universitas Lampung
}

\begin{abstract}
ABSTRAK
Penelitian berjudul "Konstruksi Makna Hijab Fashion bagi Moslem Fashion Blogger di Indonesia" dilatarbelakangi oleh perkembangan busana muslim di Indonesia yang mengalami peningkatan dalam beberapa tahun terakhir. Fenomena tersebut tidak terlepas dari pengaruh gaya hidup masa kini yang tidak dapat dipisahkan dari teknologi. Blog yang merupakan perkembangan teknologi media baru (new media) dimanfaatkan oleh para Moslem Fashion Blogger untuk mengekspresikan gaya berbusana muslim sebagai suatu trend fashion yang berperan dalam perkembangan fashion moslem di Indonesia. Peneliti ingin mengkaji lebih jauh mengenai pemahaman, motif, dan pengalaman Moslem Fashion Blogger dalam menggunakan blog sebagai media komunikasi mengenai Hijab Fashion di Indonesia. Teori yang digunakan untuk membentuk kerangka pemikiran dalam penelitian ini adalah teori fenomenologi Alfred Schutz, Teori Konstruksi Sosial Atas Realitas Luckmann dan Berger, dan Teori Interaksi Simbolik George Herbert Mead. Penelitian ini menggunakan metode kualitatif melalui pendekatan tradisi fenomenologi yang memusatkan perhatian pada pengalaman hidup dan mencari makna mengenai realitas berdasarkan sudut pandang subjek penelitian. Peneliti menetapkan enam informan sebagai sumber informasi. Hasil penelitian menunjukkan bahwa pemahaman Moslem Fashion Blogger mengenai hijab fashion adalah bahwa perkembangan tren hijab fashion di Indonesia merupakan perkembangan yang positif namun terjadi suatu pergeseran makna. Motif dalam menggunakan blog sebagai media komunikasi mengenai hijab fashion terbagi atas motif atraksi, motif inspirasi, dan motif eksistensi. Saran untuk penelitian selanjutnya adalah perkembangan hijab fashion merupakan salah satu fenomena yang menarik dan terus berkembang, maka diharapkan penelitian selanjutnya dapat mengkaji lebih mendalam khususnya mengenai konstruksi makna hijab fashion bukan hanya terhadap pelaku industri hijab namun juga lebih dalam terhadap mereka yang benar-benar memahami syariat agama Islam.
\end{abstract}

Kata-kata Kunci: hijab, fashion, moslem fashion blogger, fenomenologi, konstruksi sosial atas realitas, interaksi simbolik

\section{HIJAB FASHION CONSTRUCTION OF MEANING FOR MOSLEM FASHION BLOGGER}

\section{ABSTRACT}

The study entitled Hijab Fashion Construction of Meaning by the Moslem Fashion Blogger in Indonesia (Phenomenological Study) is started as developments of Indonesian Moslem Fashion has increased in recent years. This phenomenon can't be separated from the influence of today's lifestyle which heavily influenced by technology. Blogs which is the development of new media tecnologies (new media) used by Moslem Fashion Blogger to express the style of Moslem outfit as a current fashion, plays a significant role in the development of moslem fashion in Indonesia. This research describes motive and experience of Moslem Fashion Blogger in using blogs as a communication medium comprehension regarding hijab fashion in Indonesia. Theory forming the framework of this research are the phenomenology theory of Alfred Schutz, Social Construction of reality theory from Luckmann and Berger, and Symbolic Interaction theory of George Herbert Mead. This study eses qualitative methods and phenomenological tradition approach, which focusing on life experience and find a meaning of reality based on subject's point of view. Six informants as sources of information. The result shows that Moslem Fashion Blogger knowledge about hijab fashion on the development of hijab fashion trends in Indonesia is positive, with a slight in meaning. The motive in using blogs as a medium of communication on hijab fashion consist of attraction motives, inspiring motives, and existence motive. Suggestions for the next research are that hijab fashion development is interesting phenomenon, continues, it is suggested that the next research could examine deeper, especially in the construction of meaning on hijab fashion, not only for the industri performer, but also to those who really understand about syariah and syariat of Islam.

Keywords: hijab, fashion, moslem fashion blogger, sosial construction of reality, phenomenology, symbolic interactionism.

Korespondensi: Ade Nur Istiani, M.I.Kom. Jurusan Ilmu Komunikasi Fakultas Ilmu Sosial dan Ilmu Politik Universitas Lampung. Jl. Prof. Dr. Soemantri Brojonegoro No. 1 Bandar Lampung, 35145. Email: adenuristiani@yahoo.com 


\section{PENDAHULUAN}

Perkembangan moslem fashion di Indonesia dalam beberapa tahun terakhir mengalami peningkatan yang luar biasa. Minat masyarakat akan moslem fashion semakin hari semakin meningkat seiring dengan meningkatnya minat para desainer pakaian muslim dalam mendesain pakaian muslim yang modern. Saat ini, perkembangan moslem fashion di Indonesia mulai diakui dunia, tentu saja hal ini memberikan kesempatan yang seluas-luasnya kepada Indonesia untuk menempatkannya menjadi salah satu kiblat moslem fashion di dunia.

Fenomena perkembangan moslem fashion di Indonesia dapat dilihat dalam kehidupan seharihari dimana tren penggunaan hijab di kalangan masyarakat muslimah semakin meningkat. Perkembangan industri hijab dan moslem fashion saat ini di Indonesia dapat terlihat di kota-kota besar di pulau Jawa. Bandung sebagai salah satu pusat mode perkembangan hijab di Indonesia, dimana disetiap sudut kotanya dapat ditemui berbagai macam galeri hijab dan kawasan khusus dalam mengembangkan industri hijab fashion di sepanjang kawasan Jalan Buah Batu kota Bandung. Bermacammacam tren hijab fashion seperti keberagaman model, keberagaman warna, keberagaman motif dan keberagaman padu-padan gaya hijab dapat ditemui di sepanjang kawasan dengan adanya berbagai galeri hijab. Menurut pengamatan Ibrahim (2007: 207), fenomena perkembangan moslem fashion merupakan suatu tranformasi sosial yang menarik, pergeseran selera dan gaya muslim(ah) dalam berbusana mulai menjadi bagian dari industri fashion sejak akhir 1990an dengan "kekayaan semiotis" fashion muslim bagaimana cara, corak, asesoris dan gaya muslim(ah) berpakaian.

Kreasi gaya hijab yang terlihat disetiap galeri hijab di kota Bandung banyak menonjolkan keunikan berbagai macam bentuk fashion dalam hijab. Keberagaman gaya hijab mulai dari pakaian dengan potongan kain yang berbentuk asimetris, berbagai bentuk scarf segi empat dan pashmina dengan motif yang beragam seperti motif flowers, animal print, tie dye, etnik, polkadot serta motif lainnya yang semakin menarik dengan pemilihan warna yang segar dan tentunya tambahan aksesoris dengan berbagai macam bentuk yang cantik. Gaya hijab yang populer sekarang tentunya berbeda jauh dengan gaya hijab dahulu yang cenderung sederhana, monoton, tidak menarik, dan hanya banyak digunakan oleh muslimah yang berusia lanjut.

Gaya hijab pada masa sekarang telah menjadi bagian penting dalam industri fashion di Indonesia, hal ini pula yang membuat pemakaian hijab tidak lagi menjadi suatu pertimbangan yang berat bagi muslimah dalam memutuskan untuk berhijab. Terlebih lagi saat ini penggunaan hijab telah marak di kalangan artis, para artis yang memutuskan menggunakan hijab sudah tidak merasa takut lagi akan sepinya kontrak kerja, sebut saja para artis yang menggunakan hijab seperti Dewi Sandra, Lyra Virna, Risty Tagor, dan Inneke Kosherawati mendapat banyak tawaran kontrak kerja dan bahkan menjadi brand ambasador berbagai produk yang menonjolkan sisi kecantikan dan kepercayaan diri mereka dalam berhijab.

Internet dan perubahan teknologi telah membawa perubahan yang besar bagi manusia, dengan Internet dan segala kemudahan yang didapatkan membuat dunia terasa semakin kecil. Hal ini terjadi karena setiap orang dapat mengakses informasi apa saja kapan pun mereka mau. Hal ini dimanfaatkan oleh berbagai pihak, untuk menjalankan beragam tujuan, salah satunya termasuk sebagai media komunikasi untuk berbagi informasi mengenai busana muslim yang sekaligus mengandung pesan untuk mengajak sesama muslimah berhijab. Fenomena perkembangan fashion moslem di Indonesia salah satunya tidak terlepas dari pengaruh gaya hidup masa kini yang tidak dapat dipisahkan dari teknologi. Para muslimah memanfaatkan perkembangan teknologi sebagai sarana dalam mengapresiasikan diri mereka. Blog merupakan salah satu bentuk perkembangan teknologi media baru (new media) yang mendukung para muslimah untuk berinteraksi dan berbagi informasi.

Tren busana muslim yang telah memasuki kepopulerannya, dimana perkembangannya salah satunya didukung oleh maraknya blog yang membahas mengenai fashion moslem. Dalam Hendroyono (2013: 13), menyatakan bahwa transformasi terbesar yang dihadapi umat manusia di abad 21 adalah revolusi dari 'atoms' ke 'bits', bits is the killer app. Banyak korban berjatuhan karenanya: Borders dikalahkan oleh Amazon, toko CD dikalahkan oleh iTunes, 
penerbit dikalahkan oleh Lulu.com, layanan interlokal dikalahkan oleh skype, ensiklopedia britanica dikalahkan oleh wikipedia, koran dan majalah dikalahkan oleh blog.

Blog memiliki peranan penting dalam perkembangan tren busana muslim di Indonesia. Maraknya pemanfaatan media blog dikarenakan blog merupakan sarana media baru yang lebih efektif dan efisien. Saat ini blog dapat menggantikan peran media konvensional sebelumnya dan blog dianggap dapat memberikan informasi secara lebih mendetail dibandingkan dengan media konvensional sebelumnya. Saat ini para pengguna blog (blogger) menjadikan media blog sebagai media komunikasi atau media untuk menampilkan berbagai ide mengenai busana muslim yang menjadi ciri khas dari blogger tersebut yang mewakili tren busana muslim di Indonesia. Blogger merupakan istilah yang digunakan untuk menyebut para pengguna blog. Blog biasanya dibuat sesuai dengan topik dan tujuan dari pemilik blog (blogger).

Banyak muslimah yang menjadikan blog sebagai media mengekspresikan gaya dalam berbusana muslim sebagai suatu trend fashion dan turut menunjukkan eksistensi mereka sebagai muslimah yang berperan serta dalam perkembangan moslem fashion di Indonesia. Hal tersebut dilakukan dengan membuat suatu blog yang berisikan informasi seputaran kehidupan fashion moslem yang mereka gunakan.

Kegiatan yang dilakukan oleh Moslem Fashion Blogger bertujuan agar para pembaca blog tersebut mendapatkan referensi mengenai gaya berbusana muslim untuk kemudian menarik para pembaca blog agar meniru tren busana muslim yang dipaparkan oleh pemilik blog. Satu hal yang membuat pembaca blog tertarik biasanya karena setiap blogger dikelola oleh orang yang berbeda yang tentunya memiliki selera fashion yang berbeda pula dalam menggunakan gaya hijab. Masing-masing Moslem Fashion Blogger tersebut memiliki ciri khas sesuai apa yang ingin ditunjukkannya kepada para pengikut blog (followers), dengan tujuan agar ciri khas busana muslim para Moslem Fashion Blogger tersebut menjadi fashion panutan bagi para pengikut blog (followers). Seperti yang diungkapkan oleh Cassandra Dini Prasasti yang merupakan salah satu Moslem Fashion Blogger dan merupakan anggota Hijabers Community Bandung (Wawancara dengan Cassandra Dini Prasasti pada tanggal 19 Maret 2014):

"Hijab fashion di Indonesia sudah terjadi pergeseran makna, kalau dulu cuma untuk menutup aurat tapi sekarang dianggap tren dan makna yang ada di hijab itu sendiri sedikit pudar. Menjadikan blog sebagai media hijab, aku mau nunjukin kalau hijab dulu dan hijab sekarang tetap mempunyai makna sebagai penutup aurat tapi dapat dimix dengan style yang menarik dan memiliki ciri khas dari si blogger tersebut"

Berdasarkan fenomena yang telah peneliti paparkan di atas, bahwa blog mulai dimanfaatkan untuk mengajak sesama muslim berhijab dan sebagai suatu cara menyenangkan dalam berdakwah dengan mengedepankan fashion sebagai daya tariknya. Peneliti akan mengangkat masalah ini kedalam sebuah penelitian, karena pada dasarnya perkembangan moslem fashion di Indonesia selain didukung oleh semakin kreatifnya muslimah Indonesia dalam mengemas gaya dalam berbusana muslim, namun juga didukung oleh pemanfaatan media Internet yaitu blog.

Blog digunakan sebagai cara untuk berinteraksi dengan muslimah lainnya dalam lingkup yang lebih luas dan tidak berbatas, sehingga ini membuat pemaknaan masingmasing muslimah terhadap hijab berbedabeda. Demikian (pemaknaan tentang hijab yang berbeda) juga yang terjadi pada muslimah yang senang menggunakan blog dalam menginformasikan tren busana muslim terbaru. Perlunya blogger dalam memaknai hijab fashion agar blogger tersebut memiliki pemahaman yang baik mengenai hijab tersebut agar tidak salah kaprah dalam menampilkan hijab fashion yang sesuai dengan syariah agama. Para Moslem Fashion Blogger biasanya dijadikan tokoh inspirasi bagi pembaca blog dalam menyesuaikan moslem fashion dalam kehidupan sehari-hari.

\section{METODE PENELITIAN}

Penelitian ini menggunakan metode penelitian kualitatif dengan pendekatan fenomenologi dengan memusatkan perhatian pada pengalaman hidup, dan mencari makna dari Moslem Fashion Blogger di Indonesia atas penggunaan blog sebagai media komunikasi Hijab fashion. Metode penelitian kualitatif 
merupakan metode yang dapat mengungkapkan pemahaman, motif, dan pengalaman komunikasi mengenai fashion dalam berhijab. Dalam penelitian mengenai "Konstruksi Makna Hijab Fashion bagi Moslem Fashion Blogger di Indonesia”, peneliti menggunakan fenomenologi sebagai kunci analisis dalam penelitian. Tujuan dari penelitian ini adalah memberikan pemahaman akan makna, motif, dan pengalaman dari fenomena maraknya penggunaan hijab yang semakin beragam dan masuk dalam ranah fashion yang menarik dan menjadi salah satu perkembangan budaya Islam di Indonesia yang telah dipengaruhi budaya populer.

Teori yang digunakan dalam penelitian ini yaitu teori fenomenologi Alfred Schutz yang sebenarnya adalah kritikan Schutz atas pemikiran-pemikiran Weber dan juga Husserl tentang Sosiologi. Alfred Schutz, sosiolog yang lahir di Vienna tahun 1899 kemudian menciptakan dimensi perubahan dalam fenomenologi. Melalui berbagai upayanya, penekanannya bergeser dari subjektivitas ke intersubjektivitas, dari kesadaran pengetahuan dan makna dari intuisi mengenai esensi-esensi ke interpretasi dan tipikasi. Dia berusaha mensintesiskan filsafatnya Husserl dengan ilmu sosialnya Weber (Sobur, 2013: 50).

Dalam konteks fenomenologis, Moslem Fashion Blogger Indonesia adalah aktor yang menggunakan blog sebagai media komunikasi mengenai hijab fashion. Moslem Fashion Blogger mungkin memiliki salah satu dari dua motif, yaitu motif yang berorientasi ke masa depan (in order to motive) dan motif berorientasi ke masa lalu (because motives).

Teori Konstruksi Sosial atas Realitas Luckmann and Berger, yang merupakan salah satu mahasiswa Alfred Schutz yang mengembangkan teori ini berdasarkan kuliahkuliahnya mengenai konstruksi realitas secara sosial. Menurut Berger, sosiologi interpretatif tidak mesti terbatas pada masalah-masalah sosial psikologis namun dapat ditunjukkan oleh sintesa pendekatan interaksionis dan strukturalis. Karya Schutz membuat Berger mampu mengembangkan model teoritis lain mengenai bagaimana dunia sosial terbentuk yang tergantung pada manusia yang menjadi subjeknya. Berger berpendapat bahwa realitas sosial secara obyektif memang ada tetapi maknanya berasal dari dan oleh hubungan subjektif (individu) dengan dunia obyektif (Poloma, 2004: 298).

Teori konstruksi sosial atas realitas Berger dan Luckman, memberikan penjelasan mengenai individu (Moslem Fashion Blogger) dalam memahami pengetahuan dan pengalamannya dalam melaksanakan aktivitasnya di blog dengan konten hijab fashion dan membangun model dunia sosialnya dengan cara kerja individu lainnya yang terlibat didalam realitas tersebut saling mengkonstruksi dan merekonstruksi. Individu-individu tersebut saling membangun pemahaman akan sesuatu hal secara bersamasama. Dalam membangun pemahaman tentang hijab fashion, Moslem Fashion Blogger telah dan akan selalu membangun pemahaman bersama-sama. Peneliti harus menemukan asumsi dan bias mereka sendiri dalam rangka untuk menjelaskan realitas sehingga Peneliti dapat menemukan pemahaman para Moslem Fashion Blogger mengenai konten hijab fashion yang mereka lakukan yang ada di dalam blog yang mereka miliki.

Teori Interaksi Simbolik Herbert Mead menjelaskan bahwa di dalam teori tersebut terkandung tiga konsep utama yaitu Mind, Self dan Society. Mead mendefinisikan pikiran (mind) sebagai kemampuan untuk menggunakan simbol yang mempunyai makna sosial yang sama, dan Mead percaya bahwa manusia harus mengembangkan pikiran melalui interaksi dengan orang lain, dengan menggunakan bahasa. Diri (self) didefinisikan sebagai kemampuan untuk merefleksikan diri kita sendiri dan perspektif orang lain. Mead tidak percaya bahwa diri berasal dari instropeksi diri atau pemikiran sendiri yang sederhana. Menurut Mead diri berkembang dari sebuah jenis pengambilan peran yang khusus. Ketika Mead berteori mengenai interaksionisme simbolik, ia mengamati bahwa melalui bahasa orang mempunyai kemampuan menjadi subjek dan objek bagi dirinya sendiri. Sebagai subjek, manusia bertindak dan sebagai objek manusia mengamati diri sendiri bertindak. Mead menyebut sebagai subjek atau diri yang bertindak sebagai $I$ dan objek atau diri yang mengamati adalah $M e$. Diri adalah sebuah proses yang mengintegrasikan antara i dan $\mathrm{Me}$ (West \& Turner, 2012: 106).

Penganut interaksi simbolik berpandangan, perilaku manusia pada dasarnya adalah produk dari interpretasi mereka atas dunia di sekeliling 
mereka, perilaku dipilih berdasarkan bagaimana individu menafsirkan situasinya. Teori interaksi simbolik dalam penelitian ini berkontribusi sebagai dasar pemikiran bahwa Moslem Fashion Blogger menciptakan dan memberikan makna mengenai hijab fashion sebagai bagian dari kegiatan pemberian informasi kepada publik. Teori ini juga dapat mengkaji mengenai bagaimana tindakan yang dilakukan oleh para Moslem Fashion Blogger dalam membentuk dan memberikan makna dalam interaksi melalui simbol (hijab fashion) sehingga terdapat makna yang dipertukarkan dalam proses interaksinya yang disampaikan melalui media blog.

\section{HASIL DAN PEMBAHASAN}

Pemahaman Moslem Fashion Blogger mengenai hijab fashion dimana dalam hal ini merupakan pemahaman antara pemakaian hijab dan kaitannya dengan unsur fashion. Fashion tidak dapat terlepas dari gaya hidup masa kini, begitu pula dengan pemakaian hijab yang saat ini sudah jauh berbeda dengan pemakaian hijab yang dulu hanya sebatas sebagai pakaian muslimah yang berfungsi sebagai identitas agama bagi muslimah untuk menutup auratnya tanpa memperdulikan sisi fashion-nya. Namun, kini pemakaian hijab telah berkembang pesat dan sangat berkaitan erat dengan unsur fashion.

Pemakaian hijab yang dulu hanya sebatas sebagai identitas agama bagi muslimah, sekarang telah melebur menjadi sebuah gaya hidup bagi masyarakat muslimah modern yang menjadikan hijab sebagai bagian untuk menunjukkan identitas diri dalam kehidupan sosial. Fashion adalah semacam kode berpakaian "makro" yang menetapkan standar gaya hidup menurut usia, gender, kelas sosial dan sebagainya (Danesi, 2010: 267). Dapat disimpulkan bahwa pemahaman hijab fashion jika dikaji dari segi historisnya merupakan pemakaian hijab yang dahulu dianggap kuno dan seiring perkembangan zaman menjadi pemakaian hijab yang telah menjadi gaya hidup dan memiliki keterkaitan erat dengan fashion.

Penggunaan hijab fashion bagi muslimah pada era modern ini merupakan sebuah hasil fenomena dari konstruksi sosial atas realitas. Konstruksi sosial atas realitas merupakan proses interaksi dalam kehidupan sosial, dimana melalui komunikasi maka dunia sosial dapat terbentuk dan terjadi pemahaman yang sama mengenai dunia sosial tersebut. Konstruksi sosial tidak terbangun tanpa makna namun terdapat kepentingan-kepentingan didalamnya, realitas sosial dapat terbentuk karena individu-individu didalamnya saling melakukan interaksi dan saling mengkonstruksi dan merekonstruksi dalam realitas tersebut. Konstruksi sosial atas realitas lebih tentang bagaimana individu-individu dalam berkomunikasi dan berinteraksi akan cenderung untuk mempertanyakan mengenai aktivitas dirinya dan juga mempelajari aktivitas individu lainnya sehingga memiliki pemahaman yang sama sehingga tercipta objektivitas baru. Berger dan Luckmann berpendapat bahwa sebenarnya dalam teori konstruksi sosial atas realitas, telah terjadi dialektika antara individu menciptakan masyarakat dan masyarakat menciptakan individu. Dimana dialektika tersebut berlangsung di dalam kehidupan masyarakat secara simultan atau terjadi dalam rentang waktu yang bersamaan dengan cara membentuk pengetahuan masyarakat (Bungin, 2001: 7).

Hasil penelitian menunjukkan bahwa terlepas dari pemahaman mengenai hijab itu sendiri bagi para Moslem Fashion Blogger, tentunya para Moslem Fashion Blogger memiliki pemahaman yang berbeda-beda mengenai hijab jika dilihat terkait dari sisi fashion-nya dimana tren hijab fashion di Indonesia yang sangat populer karena perkembangannya yang semakin pesat. Berbagai macam pendapat dikemukakan oleh para Moslem Fashion Blogger mengenai tren hijab fashion di Indonesia dan bagaimana perkembangannya selama ini.

Menurut perspektif fenomenologi Alfred Schutz (dalam Sobur, 2013: 65), dunia sosial tidak berasal dari penemuan manusia itu sendiri tetapi diturunkan secara sosial dari orang-orang sebelumnya. Bisa dikatakan bahwa tindakan manusia merupakan hal yang dilihat dan ditiru dari lingkungan sosial mereka. Hal ini pula yang menjadikan bahwa kepopuleran hijab fashion di Indonesia karena hasil interaksi antar muslimah Indonesia yang terjadi secara terus-menerus dan berkesinambungan sehingga menjadikan hijab fashion di Indonesia semakin berkembang pesat.

Pemahaman mengenai hijab fashion bagi Moslem Fashion Blogger ditilik dari kaitan antara hijab dan fashion-nya, Moslem Fashion Blogger memahami hijab fashion sebagai suatu perkembangan positif dari pemakaian 
hijab yang dianggap kuno dan tidak menarik menjadi sebuah pakaian busana muslim yang menarik dan menjadikan Indonesia sebagai icon busana muslim di dunia yang memiliki berbagai macam variatif model, gaya, perpaduan warna sehingga menjadikan busana muslim di Indonesia memiliki kekhasan tersendiri. Namun, hijab fashion di Indonesia juga seakan memberikan dampak yang kurang baik dan dianggap menghilangkan nilai sakral dari kewajiban muslimah dalam menutup aurat yang membuat hijab fashion seakan-akan hanya memperlihatkan sisi duniawi dan matrealistik dalam gaya hidup muslimah modern.

Dalam pemahaman mengenai tren hijab fashion yang didapat dari penggunaan blog oleh Moslem Fashion Blogger, terdapat juga motif yang melatarbelakangi dalam penggunaan blog sebagai media komunikasi mengenai hijab fashion. Motif merupakan suatu kekuatan atau dorongan yang datang dari dalam diri untuk bertindak atau berbuat sesuatu. Dalam psikologi, dikatakan bahwa motif bersifat alami dimana sewaktu individu dilahirkan telah membawa motif-motif tertentu tetapi kemudian motif-motif yang dibawa itu sebagai akibat dari perkembangan individu maka akan mengalami perkembangan juga (Walgito, 1983: 141).

Penelitian ini berupaya untuk mengungkap motif yang ada pada Moslem Fashion Blogger dalam menggunakan blog sebagai media komunikasi mengenai hijab fashion. Terdapat berbagai macam motif yaitu motif apresiasi, motif inspirasi, dan motif eksistensi yang melatarbelakangi para Moslem Fashion Blogger dalam penggunaan blog yang berisi konten mengenai moslem fashion. Motif apresiasi yaitu Moslem Fashion Blogger menganggap bahwa blog merupakan sarana media komunikasi yang mudah, praktis, efisien dan memiliki jangkauan yang luas sehingga efektif dalam penyebaran informasinya. Berdasarkan sarana dan keunggulan yang dimiliki oleh blog.

Motif inspirasi yaitu keputusan para Moslem Fashion Blogger dalam menggunakan blog dengan konten mengenai moslem fashion, juga dilatarbelakangi dari dalam diri mereka yang memang sudah menggunakan hijab dan mencoba selalu terlihat fashionable mengikuti perkembangan zaman agar hijab tidak lagi dianggap tabu. Kesadaran Moslem Fashion Blogger mengenai pandangan penggunaan busana muslim yang dianggap tabu, kuno, dan tidak cocok digunakan oleh anak muda, membuat mereka ingin menghilangkan pandangan tersebut agar masyarakat dapat lebih terbuka dan kembali memandang bahwa menggunakan busana muslim merupakan kewajiban muslimah dan busana muslim saat ini dapat terlihat lebih menarik daripada penggunaan busana yang terbuka dan mengumbar aurat. Menurut Fiske (1990), Garmen yang merupakan salah satu butir dari fashion atau pakaian, menjadi medium atau saluran yang dipergunakan seseorang untuk menyatakan sesuatu kepada orang lain dengan maksud mendorong terjadi perubahan pada orang lain itu (Barnard, 2011: 41). Maka melalui blog, mereka seperti mendapatkan tempat yang sangat mudah sebagai media syi'ar atau dakwah untuk memperlihatkan ke masyarakat bahwa penggunaan busana muslim sudah populer dan memiliki keunikan fashion. Penggunaan busana muslim sekarang dengan ciri fashion-nya lebih dikenal dengan kata sebutan hijab. Syi'ar atau dakwah menjadi dasar Moslem Fashion Blogger untuk menjadikan blog sebagai media komunikasi dengan menampilkan fashion hijab yang selalu menarik. Profesi yang dimiliki Moslem Fashion Blogger yang berkaitan dengan dunia industri hijab seperti model, desainer busana muslim, penulis artikel majalah muslimah, dan juga public relations pada situs store online busana muslim, juga turut menjadi alasan awal Moslem Fashion Blogger memutuskan untuk menggunakan blog dengan konten hijab fashion. Profesi yang menuntut para Moslem Fashion Blogger untuk selalu mengetahui perkembangan fashion busana muslim, menjadikan Moslem Fashion Blogger harus aktif dan kreatif mencari tahu dan menciptakan tren hijab dengan fashion yang menarik. Hal ini membuat para Moslem Fashion Blogger dituntut untuk selalu dapat menyajikan konten blog yang menarik sesuai dengan perkembangan fashion hijab di Indonesia.

Motif eksistensi yaitu Moslem Fashion Blogger dalam penggunaan blog dengan konten hijab fashion, karena ingin memperlihatkan keunikan dirinya dalam padu padan busana muslim dengan paduan tren fashion dunia dan dirinya yang menggunakan hijab. Moslem Fashion Blogger mencoba mengisi konten blognya dengan memperlihatkan penggunaan busana muslim yang juga bisa digunakan bagi yang tidak menggunakan busana muslim. Cassandra juga beranggapan dengan menggunakan blog secara 
aktif dapat mempertahankan eksistensinya sebagai blogger yang telah dikenal luas tidak hanya di Indonesia.

Motif yang dijelaskan dalam penelitian ini lebih mengacu kepada alasan estetika dalam penggunaan blog dengan konten hijab fashion. Motif Moslem Fashion Blogger dalam menggunakan blog sebagai media komunikasi mengenai hijab fashion, berupaya menjelaskan mengapa para Moslem Fashion Blogger selalu mencoba untuk memperlihatkan penggunaan hijab yang menarik dan tidak terlepas dari unsur fashion. Selain itu, kreativitas Moslem Fashion Blogger dalam mengolah blog yang dimilikinya sehingga terlihat memiliki tema tersendiri ditambah dengan konten mengenai hijab fashion yang selalu diperbarui membuat nilai tambah bagi Moslem Fashion Blogger dalam memperlihatkan dan menginformasikan kepopuleran hijab fashion di Indonesia. Hal ini dapat dilihat dari blog yang dimiliki Moslem Fashion Blogger yang memiliki keunikan tersendiri yang berbeda antara satu dan lainnya, dan juga kreativitas dalam padu padan hijab fashion yang dapat dilihat dari cara mereka mengkreasikan hijab mulai dari dandanan, busana, aksesoris dan pemilihan tema dan tempat foto yang membuat konten dalam blog semakin menarik ditambah dengan penyampaian tulisan narasi yang menceritakan keseluruhan hal yang ada di dalam konten tersebut.

Moslem Fashion Blogger merasakan perbedaan ketika sebelum aktif menggunakan blog dan ketika aktif menggunakan blog dan mulai dikenal sebagai Moslem Fashion Blogger Indonesia.Blogyangdijadikanmediakomunikasi mengenai hijab fashion, membuat Moslem Fashion Blogger mendapatkan pengalaman dan wawasan yang berguna bagi dirinya sendiri dan banyak mendapatkan respon dari pengguna blog lainnya yang merasa terinspirasi karena konten blog yang mereka miliki. Blog dapat membuat portofolio yang dapat menginspirasi masyarakat mengenai wawasan Islam, dimana hal tersebut juga memberikan manfaat bagi dirinya sendiri karena dapat mencari tahu dan mengetahui hal yang sebelumnya tidak diketahuinya. Menggunakan blog yang awalnya hanya sebagai hobi dan wujud dari ekspresi diri, ternyata membuka kesempatan bagi Moslem Fashion Blogger untuk mendapatkan profesi yang dianggap sesuai dengan minat dan bakat yang mereka miliki. Selain mendapatkan banyak manfaat ketika dikenal sebagai Moslem Fashion Blogger, berbagai pandangan yang tidak baik juga dirasakan oleh mereka, seperti adanya tanggapan negatif mengenai hal yang ada di dalam konten blog Moslem Fashion Blogger. Berbagai tanggapan yang kurang baik dijadikan sebagai bahan pembelajaran untuk dirinya agar lebih baik lagi. Selain mendapatkan banyak manfaat ketika dikenal sebagai Moslem Fashion Blogger, berbagai pandangan yang tidak baik juga dirasakan oleh mereka, seperti adanya tanggapan negatif mengenai hal yang ada di dalam konten blog Moslem Fashion Blogger.

\section{SIMPULAN}

Pemahaman Moslem Fashion Blogger mengenai hijab fashion di Indonesia dinilai sebagai tren positif dan tren negatif adanya pergeseran makna. Moslem Fashion Blogger memiliki beragam motif dalam menggunakan blog sebagai media komunikasi mengenai hijab fashion yang terdiri dari motif atraksi, motif inspirasi, dan motif eksistensi. Moslem Fashion Blogger mendapatkan pengalaman dalam menggunakan blog sebagai media komunikasi mengenai hijab fashion, dimana merasa mengalami perbedaan ketika belum dikenal sebagai blogger dan ketika telah menjadi blogger. Pengalaman setelah menjadi blogger yakni Moslem Fashion Blogger merasa mendapatkan wawasan mengenai perkembangan hijab fashion di Indonesia dan juga merasa memiliki konsep diri yang baik dan lebih terkonsep dalam menyampaikan konten mengenai hal apa yang ingin dibagi dalam blog. Selain itu, pengalaman setelah menjadi blogger yakni Moslem Fashion Blogger merasa lebih dikenal, karya hasil mereka lebih dihargai dan juga mendapatkan profesi yang berkaitan dalam industri hijab serta mendapatkan produk-produk hijab dan memperlihatkannya dalam konten blog. Hijab fashion di Indonesia memberikan banyak manfaat dalam perkembangan pemakaian busana muslim di Indonesia. Terlepas dari beragam hal positif yang didapat karena perkembangan hijab fashion, ternyata tidak terlepas pula dari pandangan skeptis mengenai muslimah yang menggunakan busana muslim secara perlahan menghilang dan sekarang terbentuk kelas sosial tersendiri dan hijab fashion sudah menjadi bagian dari 
gaya hidup muslimah pada era modern ini. Blog memberikan kemudahan bagi muslimah untuk saling berinteraksi dan menginspirasi dalam semua hal yang berkaitan dengan keindahan muslimah dalam menutup aurat dan juga berbagi pengalaman mengenai Islam.

Telah terjadi pergeseran makna Hijab fashion dan ada anggapan hanya mementingkan penampilan muslimah secara duniawi saja, sebaiknya para Moslem Fashion Blogger atau trendsetter hijab memberikan contoh yang baik mengenai pemakaian hijab yang menutup aurat sesuai dengan ketentuan dalam agama Islam. Selain itu, konten yang disajikan tidak hanya mengenai hijab dan fashion-nya saja tetapi terdapat unsur dakwah mengenai ilmu pengetahuan agama Islam. Pemanfaatan dari perkembangan media baru yaitu blog merupakan media komunikasi yang baik dalam menyampaikan suatu kultur dan fenomena tertentu. Sebaiknya untuk penelitian fenomenologi selanjutnya, dapat mengkaji mengenai perananan media dalam membangun suatu kultur menjadi fenomena yang memberikan dampak perubahan yang berguna dan bermanfaat bagi masyarakat. Selain itu, diharapkan terdapat penelitian lanjutan mengenai perkembangan hijab di Indonesia yang terkait dengan suatu budaya.

\section{DAFTAR PUSTAKA}

Barnard, M.(2011).Fashion sebagaikomunikasi cara mengomunikasikan identitas sosial, seksual, kelas, dan gender. Yogyakarta: Jalasutra.

Bungin, B. (2001). Metodologi penelitian kualitatif aktualisasi metodologis ke arah ragam varian kontemporer. Jakarta: Raja Grafindo Persada.

Hendroyono, H. (2013). Brand gardener edisi khusus tumbuh berkembang. Jakarta: Literati.

Ibrahim, I. S. (2007). Budaya populer sebagai komunikasi. Yogyakarta: Jalasutra.

Poloma, M. M. (2004). Sosiologi kontemporer. Jakarta: Raja Grafindo Persada.

Sobur, A. (2013). Filsafat komunikasi tradisi dan metode fenomenologi. Bandung: Remaja Rosdakarya.

Walgito, B. (1983). Psikologi umum. Yogyakarta: Yayasan Penerbitan Fakultas Psikologi UGM.

West, R. \& Turner, H. L. (2012). Pengantar teori komunikasi: analisis dan aplikasi. Jakarta: Salemba Humanika. 